\title{
SENSORY ASYMMETRY ASSESSMENT OF 8-11 YEARS OLD CHILDREN WITH AND WITHOUT LEARNING DISABILITIES
}

DOI: $10.24234 /$ se.2021.3.1.263

\author{
AUTHORS' DATA: \\ Tereza Azatyan, $\mathrm{PhD}$ in Education, Associated professor, Head of Chair \\ Chair of Special Pedagogy and Psychology, \\ Khachatur Abovyan Armenian State Pedagogical University, Armenia \\ Contacts: azatyantereza41@aspu.am
}

\begin{abstract}
Symmetry-related symptoms may be important seems to be very important while child development and schooling. In science, there are two approaches for the evaluation of hemispheric differences: method of determination "of rucote" through the survey (Edinburgh test) and the method of active identification of motor and sensory asymmetry by Bragina and Dobrokhotova. The methods are widely represented in the modern scientific literature, but no studies have been found that assessed the relationship between the results of testing the functional asymmetry of the brain using the Edinburgh test and tests to determine motor and sensory asymmetry. For this purpose, the author studied and tested research methods aimed at the examination of the inter hemispheric asymmetry in normally developing and mentally retarded children aged 8-11 years identifying the degree of inter hemispheric interaction.

The research was carried out in the scientific laboratory of the faculty of special and inclusive education of the Khachatur Abovyan Armenian state pedagogical university.

The study involved a total of 131 children aged 8 to 11 years, 73 of them are healthy schoolchildren, as well as 58 children with mild mental retardation.
\end{abstract}

Keywords: sensory asymmetry, techniques, tests, mental retardation, assessment, speech asymmetry, visual asymmetry, inter hemispheric interaction 


\section{INTRODUCTION}

So far in science, there are two approaches for the evaluation of hemispheric differences: method of determination "of rucote" through the survey (Edinburgh test) (Luria, 1973; Oldfield, 1971) and the method of active identification of motor and sensory asymmetry by Bragina and Dobrokhotova (Bragina \& Dobrokhotova, 1988). The Edinburgh test is widely used in the world: it is used in the study of behavior (Pankova \& Romanov, 2014), emotions (Aron, et al., 2005), and as a preliminary test for the selection of participants in neuroimaging studies (Mikhailov \& Tkachenko, 2009). Test for the determination of the leading limb and the lead eyes were used to assess the impact of the lateralization of the brain to intelligence and mathematical ability (Khokhlov \& Kovyazina, 2013), when studying the adaptation possibilities and physical development of boys and girls, as well as the formation of the stress resistance of the organism (Lisova \& Shilov, 2015; Ananyev, 1990). This implies that both methods are widely presented in the modern scientific literature, but we have not found studies that would assess the relationship between the results of testing functional asymmetry of the brain using the Edinburgh test and tests for the determination of motor and sensory asymmetry.

Functional studies were conducted in the morning, in conditions that meet the hygienic requirements for educational institutions (San PiN 2.4.2.2821-10, 2013). The study complied with the ethical requirements set out in the Helsinki Declaration (The World Medical Association, INC, 2008).

\section{MATERIALS AND METHODS OF RESEARCH}

The research was carried out in the scientific laboratory of the faculty of special and inclusive education of the Khachatur Abovyan Armenian state pedagogical university. The study involved a total of 131 children aged 8 to 11 years, 73 of them are healthy schoolchildren, as well as 58 children with mild mental retardation.

The degree of mental retardation was assessed on medical grounds, the degree of social adaptation, the degree of intellectual functioning, and the development of the school curriculum in the process of training in a special educational institution.

Each category surveyed was divided into 2 age groups: 8-9 years and 10-11 years. Control group of healthy schoolchildren: 
- $8-9$ years - 38 children, including 20 girls and 18 boys;

- $10-11$ years 35 children of them 17 girls and 18 boys;

The Experimental group of children with mental retardation:

- 8-9 years - 28 children, including 11 girls and 17 boys;

- $10-11$ years 25 children of them 12 girls and 13 boys;

Children were selected for the experimental group on the basis of accompanying documents with an approved diagnosis of "mild mental retardation". After reviewing the results of

clinical, laboratory, pedagogical and psychological examinations with family members and guardians signed a voluntary agreement on the participation of the child in research.

\section{TESTING METHODOLOGY}

Functional studies should be carried out in the morning, in conditions that meet the hygienic requirements for educational institutions. When conducting the study, observe the ethical requirements prescribed by the Helsinki Declaration (The World Medical Association, INC, 2008).

\section{A. assessment of auditory and auditory-speech asymmetry:}

To determine the lateralization of auditory-speech functions, the method of dichotic listening with the definition of the "right ear coefficient" (CPU) is used. Dichotic stimulation can be carried out with two sets of verbal stimuli (words) presented simultaneously through separate channels through headphones in both ears. This technique requires special equipment, while one of our tasks was to use available methods that we could recommend to school psychologists for diagnostic purposes. In this connection, we have taken the following methods: test "Whisper" (Bragina \& Dobrokhotova, 1988); test "ticking hours" (Leutin, 2007). In this case, if the test reveals the dominance of the right ear, we put +1 point, if the dominance of the left ear- 1 point. A zero score is assigned for undetected dominance of the right or left ear.

To study hearing asymmetries, you can use simple, publicly available techniques and techniques that require the use of special devices.

Test "whisper". The experimenter says something to the test subject in a whisper. In case of an equality of hearing acuity, the test subject substitutes to the speaker a leading ear, i.e. the ear heard by which is realized easier and faster. 
Test "ticking clock". The test subject is asked to estimate the volume of the clock ticking with both ears. At the same time, it is pointed out to which ear he brings the clock for the first time and whether different ears hear the same volume of ticking. It can be noted which ear the test subject puts forward, listening to something (Leutin, 2007; Annett \& Kilshow, 1982).

Test "tuning fork". The duration of the tuning fork is determined, which is brought alternately to the right and left ear.

\section{B. assessment of visual asymmetry}

The following tests are used to determine the leading eye:

1. Test "blinking one eye". The test subject is asked to blink one eye. Usually, the ignorant eye is closed.

2. Test "Rosenbach". The test subject holds a pencil vertically in his outstretched hand and fixes it with his eyes on a certain point (better in relation to any vertical line), spaced 3-4 $\mathrm{m}$, both eyes are open. Then the test subject alternately closes one and the other eye. The leading eye is considered to be the eye when closing which the pencil moves in its direction (Luria, 1973).

3. Test "Card with a hole". A $1 \times 1 \mathrm{~cm}$ hole is cut in a sheet of thick paper. Keeping this card at a small distance from the eye, the test subject views the object; the viewing is usually performed by the leading eye (Annett \& Kilshow, 1982; Bragin \& Dobrokhotova, 1988).

4. Self-assessment of the test subject-the answer to the question of what eye he aims for.

\section{RESULTS}

\section{Auditory asymmetry}

The frequencies and intensities characteristic of speech are in the center of the human audibility zone: from 20 to $16,000 \mathrm{~Hz}$. Out of human hearing are ultrasonic frequencies - more than $16 \mathrm{kHz}$ and infrared-less than $20 \mathrm{~Hz}$.

Test "Listen to the ticking of the clock".

The acuity of hearing on both ears is different. The best sensitivity of the left ear is shown. The predominance of the left ear was $50 \%$ of the test subjects, right - $7 \%$ symmetry $43 \%$ in the study of audiometer and in the study of the tuning-fork - 50,36 and $14 \%$ of test subjects, respectively (Neimark, 1954). In distinguishing the height of dichotic chords (1650 and $1750 \mathrm{~Hz}$ ), 
alternately presented to one or the other ear through headphones at a sound pressure level of 80 $\mathrm{dB}$, the left ear prevailed in $75 \%$, the right in $25 \%$ of the subjects (Gregory A., 1982).

Visual asymmetry

Human vision perceives "electromagnetic radiation in the wave range from 400 to $750 \mathrm{~nm}$ " (Grusser, 1985). In binocular vision, the visual impressions of each eye have different strength and quality, "outweighs the impressionable ability of one of the eyes and this prevalence more often in the right eye". At $92.6 \%$ of the studied individuals established asymmetry: right - at $62.6 \%$, left-sided - $30 \%$, symmetry-7.4\%. Binocular vision - "the addition of various monocular features" that is "perfect" functions for each eye separately (Ananyev, 1960).

One of the main functions of the visual analyzer, considered in the aspect of inter hemispheric relations, is binocular vision.

The course of determining the asymmetry of the visual analyzer revealed that $60 \%$ of schoolchildren aged 8-11 years have the right leading eye, left-15.8\% and 24.2\% - mixed type. Despite the fact that binocular vision, visual impressions of each eye have a different ability, that is, one eye acquires a leading value (often the prevalence of the right eye), and the other - a subordinate. Most children have predominant right eye functions, probably because the left hemisphere is involved in the processing of verbal information.

\section{CONCLUSION}

Complex disorders of cognitive activity in children with mental retardation are due to both general underdevelopments of the brain and changes in inter hemispheric interaction underlying the integration of brain functions. In mental retardation, there is a global, undifferentiated left hemisphere response - this" Gestalt " type of response is normally more characteristic of the right hemisphere. The deficit of the functions of the right hemisphere is manifested in the violation of the visual-spatial and holistic nature of perception. More rudely, than with mental retardation reveals a violation of inhibitory functions cortex. Violation of inter hemispheric transfer of information distorts the cognitive integration of intellectual activity.

The presence of a third of boys and about $40 \%$ of girls left-sided profile of individual brain asymmetry is due, as a rule, disorders of the left hemisphere, manifested in the global, 
undifferentiated response of the left hemisphere to significant and insignificant stimuli of visual perception.

Of all the asymmetries in our work, the main importance is given to the right-left hemisphere. Right-left reflects, apparently, the most fundamental dissimilarity of the brain's hemispheres, within which all other asymmetries of the hemispheres manifest themselves.

In the course of widespread studies of functional asymmetry of the brain, it is becoming increasingly obvious that the ideas about the autonomy of each of the hemispheres in providing different types of human activity, that as a result of splitting the brain, a person receives, as it were, two brains instead of one.

Clinical experience suggests that neither the left nor the right hemisphere of the brain has advantages. Regardless of the side of brain damage, patients with focal brain damage find a decrease or even impossibility of social adaptation.

The functional contribution of the right and left hemispheres to the formation of the human psyche is assumed to be different because the hemispheres in their paired work function dissimilar in time. Pair work is carried out in the present time so that the right hemisphere is based on the past, the left - on the future time. Therefore, the preservation of paired hemispheres and the structural integrity of the brain - the main condition, without which it is impossible to form a full mental activity.

\section{REFERENCE LIST}

1. Ananyev, B., G. (1990). Psikhologiya chuvstvennogo poznaniya (Psychology of Sensory Cognition), Moscow: Akad. Ped. Nauk SSSR.

2. Annett, M., \& Kilshow, D. (1982). Mathematical ability and lateral asymmetry. Cortex, Vol. 18 (46), 547-568. doi: 10.1016/S0010-9452(82)80053-1.

3. Aron, A., Fisher, H., Mashek, D., Strong, G., Li, H., \& Brown, L. (2005). Reward, motivation, and emotion systems associated with early-stage intense romantic love // Journal of neurophysiology. No 1. - V. 94. - P. 327-337.

4. Bragina, N., \& Dobrokhotova, T. (1988). Functional asymmetries of a person, 2nd ed. Revised and add. - M.: Medicine. - 237 p. 
5. Khokhlov, N., \& Kovyazina, M. (2013). Lateral signs, structural-level characteristics of intelligence and mathematical abilities; //Asymmetry magazine. - No 3. - V. 7. - P. 32-52.

6. Leutin, V., P. (2007). Brain asymmetry and human adaptation /Asymmetry, № 1. - C. 7173.

7. Lisova, N., \& Shilov, A. (2015). The role of activation processes of the cerebral cortex in the formation of stress resistance in students with different temperamental characteristics // Siberian Bulletin of Special Education. No 2 (15). - P. 52-57.

8. Luria, A., R. (1973). The working brain: An introduction to neuropsychology. New York, NY: Basic Books.

9. Mikhailov, I., V, \& Tkachenko, P., V. (2009). Research capabilities of the status of human peripheral neuro-muscular apparatus in clinic and experiment. Mezhdunarodniy zhurnal prikladnykh i fundamentalnykh issledovaniy. (5): 25-8. Russian.

10. Oldfield, R., C. (1971). The assessment and analysis of handedness: The Edinburgh inventory. Neuropsychologia, 9(1), 97-113

11. Pankova, N., \& Romanov, S. (2014). Dynamics in the academic year of behavioral manifestations and quantitative indicators of functional inter hemispheric asymmetry in students // Scientific Prospects of the 21st Century. Achievements and prospects of the new century: III International Scientific and Practical Conference, Novosibirsk, August 15-16, - No 3. - Part 5. - Novosibirsk: International Scientific Institute «Education».

12. San PiN 2.4.2.2821-10, (2013). Sanitarno-epidemiologicheskie pravila i normativi.

13. The World Medical Association, Inc. (2008). Declaration of Helsinki Ethical Principles for Medical Research Involving Human Subjects. 